\title{
The Sixth World Congress of Cardiology
}

The 6th World Congress of Cardiology was held in London from 6 to 12 September 1970 under the gracious patronage of Her Majesty the Queen and with a distinguished array of Vice-Patrons. It was sponsored by the International Society of Cardiology (president Sir Kempson Maddox). Professor Sir John McMichael, President of the British Cardiac Society, was President of the Congress. The Royal Festival Hall complex on the South Bank provided a Conference Centre well able to contain the 5300 who registered, of whom 4000 were participants.

The Organizing Committee with Professor J. P. Shillingford as Chairman and Professor J. F. Goodwin as Vice-Chairman began preparations in 1968. The main objective was to plan a scientific programme worthy of an assembly of cardiologists from all parts of the world. This duty was assigned to the Scientific Committee under the Chairmanship of Professor C. T. Dollery. The importance of fluent communication between speakers and audience was considered paramount and the purpose of ensuring that speakers used good slides, that they were projected effectively, and that the audience could see and listen in comfort was entrusted to the Audio-Visual Committee under Dr. D. Mendel and Dr. P. Hansell.

Each morning, a single plenary session was devoted to a review of recent advances by international authorities in a series of selected subjects; five concurrent round table sessions occupied the first half of each afternoon and free communications sessions, the latter half. Plenary sessions on paediatric cardiology, the myocardium, and cardiomyopathy were particularly notable. An entire morning was devoted to replacement of heart valves, at which some of the world's leading cardiac surgeons presented results which permitted comparisons between different approaches to the problem. Of the round table sessions, that devoted to the electrical activity of the heart attracted great interest, while a session on the

- place of surgery in the management of ischaemic heart disease provoked lively exchanges between the speakers, indicating how much more controversial some of the topics would have been if audience participation had been possible. Another afternoon session on cardiac transplantation showed how careful and undramatic research has pointed to the possibilities of transplantation as a technique with indications analogous to other contemporary cardiac operations. A memorable feature was the colour $\mathrm{E}$ idophor demonstrations arranged by CIBA Laboratories Ltd. These consisted of live colour television transmissions onto three large screens. By this medium, practical demonstrations with authoritative commentaries on blood flow measurement, intensive care, and mechanical circulatory assistance reached audiences of over 3000 .

An efficient system of stewarding was provided by a team of indefatiguable medical students, stewards from St. Mary's Hospital Medical School directed by Mr. Michael Shillingford, and stewardesses from the Middlesex Hospital Medical School led by Miss Linda Marks.

The Publications Committee, with Dr. S. Oram as Chairman, organized the assembly and publication of the proceedings in special issues of the British Heart fournal and Cardiovascular Research. A trade exhibition of scientific equipment, medical literature, and pharmaceutical products was staged under the direction of Dr. M. K. Towers and Dr. P. Cliffe.

From its initiation the Organizing Committee had looked forward with pleasure to entertaining the delegates and their families when the day's scientific programme had ended. The Social Committee (Dr. W. Somerville, Chairman) was charged with arranging a series of evening diversions, making use of the attractions and pageantry of the London scene. The riverside setting of the Royal Festival Hall provided a dramatic background to the red-coated Guards bands and fireworks display, the dignity of Lancaster House for Her Majesty's Government reception, the pomp and splendour of the Guildhall for the Lord Mayor's reception. The Royal Colleges, British Medical Association, Royal Society of Medicine, Wellcome Foundation, Commonwealth Institution, and the Apothecaries' Hall were the scenes of other receptions, some of them by courtesy of leading industrial concerns. On other nights, the visiting delegates and their families were entertained at their embassies, and at a concert by the Hallé orchestra and at a Gala Performance of 'The Magic Flute' by the Sadler's Wells Opera Company.

The social programme was reinforced by a Ladies' Programme, arranged by a dynamic and forward-looking ladies' Committee with Mrs. E. B. W. Cardiff as Chairman. The 
activities included tours of London, expeditions to Oxford, Cambridge, Brighton, Chichester and other famous tourist attractions, and visits to Stately Homes, some of them specially opened for the distinguished guests. Two fashion shows, by courtesy of Marks and Spencer, were presented to overflow audiences.

The firm financial structure of the Congress from its earliest planning days was designed by $\mathrm{Mr}$. H. H. Blandford and $\mathrm{Mr}$. G. A. Barnes. Generous support was provided in the form of interest-free loans, donations in cash, and other forms of material aid from the British Heart Foundation and a large number of learned medical and public bodies and industrial organizations, many of them pharmaceutical concerns.

The meetings of the various committees were arranged and co-ordinated by Miss E. G. North. The innumerable details of professional organizing, including liaison, correspondence, and transport arrangements, were in the hands of Conferences Services Ltd.; their experience and efficiency strengthened the organizing committee through the years of preparation. 